\title{
Uterine cancer presenting as obstructive jaundice
}

\author{
This article was published in the following Dove Press journal: \\ International Journal of Women's Health \\ 7 July 2016 \\ Number of times this article has been viewed
}

\section{Valdano Manuel \\ Eserval Rocha \\ Giovana Fortini \\ Zeida Pascoal \\ Renata Netto \\ Lenira Rengel \\ Claudio Birolini \\ Edivaldo Massazo Utiyama}

Department of General and Trauma Surgery, Hospital das Clínicas, School of Medicine, University of São Paulo, São Paulo, Brazil Revolução de Outubro Avenue,

225, Luanda, Angola

Tel +244925402326

Email valdanympub@gmail.com
Correspondence: Valdano Manuel

\begin{abstract}
Obstructive jaundice as an initial manifestation of uterine cancer is extremely rare. We present a case of a 72-year-old female who presented with obstructive jaundice, supposedly for pancreatic cancer. After detailed diagnostic investigation, the cause of the jaundice was attributed to a metastatic compression of the common bile duct, from the primary neoplasm of the uterus. This case highlights the importance of including uterine cancer in the differential diagnosis of woman presenting with obstructive jaundice, even though it is very rare.
\end{abstract}

Keywords: obstructive jaundice, uterine cancer, pancreatic metastasis, bile ducts

\section{Introduction}

The majority of the tumors that can cause obstructive jaundice originate from pancreatic, biliary, or periampullary sites. ${ }^{1-2}$ There are other tumors that cause external compression of the biliary channels resulting in obstructive jaundice, the most frequent are primary carcinomas of the stomach, colon, rectum, esophagus, kidney, and lung. ${ }^{1-3}$ Pancreatic metastasis from a primary cancer of the uterus cervix is extremely rare with few cases reported. ${ }^{4-9}$

In this report, we present a case of obstructive jaundice initially attributed to pancreatic cancer. Detailed radiological, pathological, and laboratory investigation clarify that the cause of the obstructive jaundice was metastases from a primary malignant cancer of the uterus.

\section{Case report}

A 72-year-old female with no history of cancer or gallstones presented with complaints of pain in the upper right abdomen and yellowish discoloration of the eyes and skin, for the past 6 months. She reported weight loss of $10 \mathrm{~kg}$. On clinical examination, vitals signs were stable, icterus was present, and no peripheral lymphadenopathy was observed. The abdomen was slightly distended but smooth, and the gall bladder was palpable on the right upper quadrant of the abdomen.

Laboratory data were total bilirubin $4.8 \mathrm{mg} / \mathrm{dL}$; direct bilirubin $4.3 \mathrm{mg} / \mathrm{dL}$; indirect bilirubin $0.5 \mathrm{mg} / \mathrm{dL}$; alkaline phosphatase $434 \mathrm{U} / \mathrm{L}$; gamma-glutamyltransferase $744 \mathrm{U} / \mathrm{L}$; alanine aminotransferase $303 \mathrm{U} / \mathrm{L}$; aspartate aminotransferase $604 \mathrm{U} / \mathrm{L}$; lipase $78 \mathrm{U} / \mathrm{L}$; and amylase $101 \mathrm{U} / \mathrm{L}$. Tumor markers were CA125 122 U/mL; CA15.3 $60 \mathrm{U} / \mathrm{mL}$; CA19.9 $394 \mathrm{U} / \mathrm{mL}$; and CA $72.49 \mathrm{U} / \mathrm{mL}$.

Abdominal and pelvis computed tomography (CT) scan revealed retropancreatic and periaortic images suggestive of lymphadenomegaly involving the distal choledocus (Figure 1A and B). A solid mass in the uterus cervix without cleavage plane with the posterior wall of the bladder was also observed. This tumor was involving the distal 

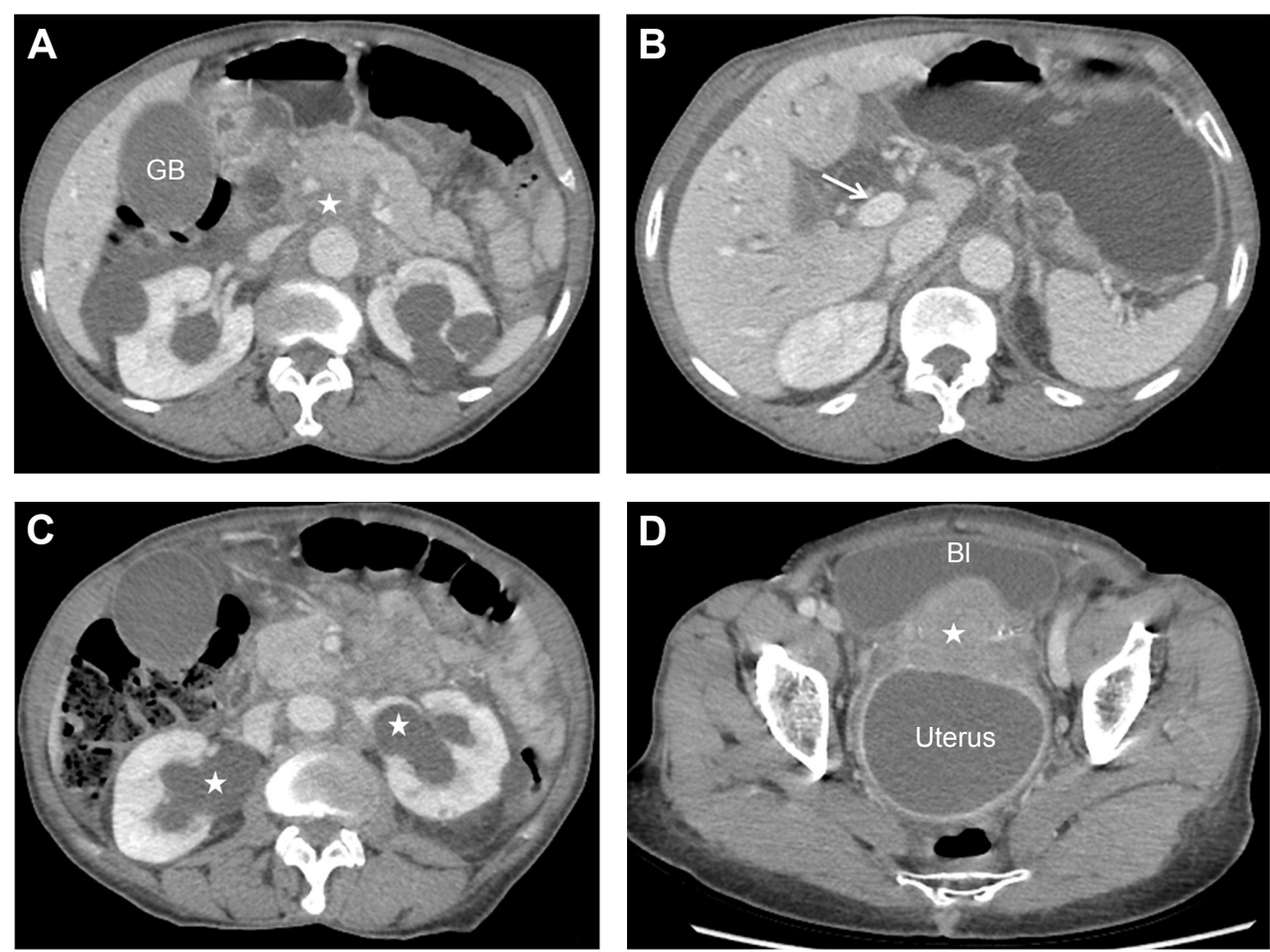

Figure I Abdominal and pelvis computed tomography scans.

Notes: (A) Gallbladder (GB) distention and retropancreatic and periaortic images suggestive of lymphadenopathies (star). (B) Choledochal dilation (arrow). (C) Bilateral hydronefrosis (stars). (D) A solid mass of the cervix suggesting a primary cancer (star), and a cystic formation with hypodense content matching with distended uterine cavity. Bladder $(\mathrm{BI})$ imaging.

ureters resulting in bilateral hydronefrosis (Figure 1C). A cystic formation with hypodense content matching with distended uterine cavity containing mucus/old hematic material, causing displacement of the bladder, and compression on the upper rectum and distal sigmoid (Figure 1D), was also noted. There was no evidence of peritoneal carcinomatosis or involvement of other organs.

Vaginal examination confirmed a large mass in the uterine cervix. Transvaginal ultrasound revealed a heterogeneous cervix without endocervical canal evidence and a uterine cyst with a thick content inside. The biopsy from the cervix showed an invasive squamous-cell carcinoma, moderately differentiated. A diagnosis of primary neoplasm of the cervix stage IIIB/IV was established.

An endoscopic retrograde cholangiopancreatography (ERCP) and drainage of the choledocus with endoprothesis was performed. The patient's cholestasis improved and she was referred for further oncological treatment.

\section{Discussion}

Obstructive jaundice can be caused by compression of the bile ducts due to intra- or extra-hepatic lesions. Extra-hepatic causes are divided into intra-ductal and extra-ductal etiologies. Neoplasms, choledocholithiasis, biliary strictures, parasites, and primary sclerosing cholangitis lead the intra-ductal obstruction causes. Tumors involving the pancreas, biliary, or periampullary region and cystic duct stone lead the extra-ductal obstruction causes. The majority of the tumors involving the pancreas are primary, or have biliary or periampullary origins. ${ }^{1-8}$ Metastatic pancreatic cancer is rare, with a reported frequency ranging from $2 \%$ to $5 \%$ of all pancreatic malignant tumors. ${ }^{1-3,8-10}$

Metastasis to the pancreas from uterine cancer is an extremely rare cause of obstructive jaundice, ${ }^{4-9}$ obstructive jaundice as initial manifestation of uterine cancer is the rarest. ${ }^{4-9}$ In this case, the patient presented due to the jaundice, this sign can confound the diagnosis, mimicking primary pancreatic lesion. Distinguishing primary pancreatic cancer from pancreatic metastasis of cancers arising elsewhere in the body is not easy. ${ }^{2,4}$ Further investigation including ultrasound imaging, CT scan, magnetic cholangioresonance, ERCP, percutaneous cholangiography, and endoscopic ultrasound biopsy may be required. ${ }^{3,4-10}$ In this case, the abdominal ultrasound performed at admission was inconclusive. The abdominal CT performed was essential for the diagnosis of pancreatic metastasis and to identify the primary tumor. Although surgical resection of pancreatic metastasis have been reported, there are no guidelines for the management 
of these patients. ${ }^{2-10}$ Surgical resection is often advocated for single lesion and for patients with clinical condition to perform a pancreatectomy. The usefulness of pancreatic resection is mainly linked to the biology of the primary tumor metastasizing to the pancreas. ${ }^{2,8}$ Endoscopic biliary drainage is a palliative approach when surgery is not possible. ${ }^{4}$ Our patient was submitted to endoscopic biliary drainage and improved of the cholestasis, thus creating a better clinical condition in order to start adjuvant oncological therapy.

\section{Conclusion}

The current case clearly shows the importance of high suspicion of uterine cancer in woman presenting with obstructive jaundice, eventhough it is uncommon. Abdominal CT plays a key role in the diagnosis of the primary lesion.

\section{Acknowledgment}

The ethics committee of Hospital das Clinicas, School of Medicine, University of São Paulo, approved the study. The participant provided informed written consent.

\section{Disclosure}

The authors report no conflicts of interest in this work.

\section{References}

1. Adsay NV, Andea A, Basturk O, et al. Secondary tumors of the pancreas: an analysis of a surgical and autopsy database and review of the literature. Virchows Archiv. 2004;444:527-35.

2. Sperti C, Moletta L, Patanè G. Metastatic tumors to the pancreas: the role of surgery. W J Gastro Oncology. 2014;6:381.

3. Moon SG, Han JK, Kim TK, et al. Biliary obstruction in metastatic disease: thin-section helical CT findings. Abdom Imaging. 2003;28:45-52.

4. Levey JM. Endoscopic biliary drainage for metastatic squamous cell carcinoma of the cervix. Gastro Endoscopy. 2000;51:97-9.

5. Wastell C. A solitary secondary deposit in the pancreas from a carcinoma of the cervix. Postgraduate Med J. 1966;42:59-61.

6. Mackay B, Osborne BM, Wharton JT. Small cell tumor of cervix with neuroepithelial features: ultrastructural observations in two cases. Cancer. 1979;43:1138-45.

7. Kuwatani M, Kawakami H, Asaka M, et al. Pancreatic metastasis from small cell carcinoma of the uterine cervix demonstrated by endoscopic ultrasonography-guided fine needle aspiration. Diagn Cytopathol. 2008; $36: 840-2$.

8. Ogawa H, Tsujie M, Miyamoto A, et al. Isolated pancreatic metastasis from uterine cervical cancer: a case report. Pancreas. 2011;40:797-8.

9. Nishimura C, Naoe H, Hashigo S, et al. Pancreatic metastasis from mixed adenoneuroendocrine carcinoma of the uterine cervix: a case report. Case Rep Oncol. 2013;6:256-62.

10. Smith AL, Odronic SI, Springer BS, Reynolds JP. Solid tumor metastasis to the pancreas diagnosed by FNA: a single-institution experience and review of the literature. Cancer Cytopathology. 2015;123:347-55.
International Journal of Women's Health

\section{Publish your work in this journal}

The International Journal of Women's Health is an international, peerreviewed open-access journal publishing original research, reports, editorials, reviews and commentaries on all aspects of women's healthcare including gynecology, obstetrics, and breast cancer. The manuscript management system is completely online and includes

\section{Dovepress}

a very quick and fair peer-review system, which is all easy to use. Visit http://www.dovepress.com/testimonials.php to read real quotes from published authors. 